\title{
Trends and Prospects in Metacognition Research ${ }^{1}$
}

\author{
Esteban Montenegro Montenegro \\ Instituto de Investigaciones Psicológicas, Universidad de Costa Rica \\ Dirección postal: 11501-2060, Universidad de Costa Rica \\ Ce: estebanmontegmail.com
}

Desde que fue acuñado por Flavell (1979), el constructo metacognición ha propiciado mucha discusión y análisis tanto en psicología básica como en psicología aplicada. Esta habilidad, llamada metacognición es definida por Flavell (1979) como el pensamiento acerca del pensamiento. Desde entonces y partir de esa caracterización se han publicado cuantiosos artículos sobre la metacognición y cómo esta interviene en la regulación y el monitoreo del propio pensamiento.

De esta forma, tras más de 30 años de investigación y análisis, dos prominentes expertas en el tema, Anastasia Efklides, docente e investigadora de la Universidad Aristotélica de Thessaloniki, en Grecia y Pluosia Misailidi, profesora de la Universidad de Ioannina, en Grecia, retoman artículos de reciente data elaborados por renombrados investigadores, quienes plasman revisiones e investigaciones empíricas aplicadas y básicas en esta temática. Así, el libro está divido en dos grandes partes; en la primera de ellas se destacan diez artículos donde se retoman investigaciones básicas en metacognición. En la segunda parte del libro Efklides y Misailidi (2010) recopilan diez artículos referidos a las implicaciones educativas del estudio de la metacognición y su desarrollo en el ciclo vital.

En la primera parte del libro sobresale el artículo de Beran y colaboradores quienes realizan una reseña de sus hallazgos principales en torno a la metacognición en sujetos no humanos utilizando el paradigma de monitoreo de la incertidumbre en macacos y ratas. Si bien es un procedimiento

1 Efklides, A. \& Misailidi, P. (Eds.). (2010). Trends and Prospects in Metacognition Research. New York: Springer. ISBN: 978-14419-6545-5 
polémico por su traslape con el condicionamiento operante, es un capítulo como pocos en esta materia, dedicado a la discusión de la presencia o no de estrategias metacognitivas en animales, aportando así insumos a la investigación comparada en este constructo.

Por su parte, Scott y Dienes presentan en esta obra el modelo del procesamiento dual del aprendizaje artificial de la gramática trazado a partir de los resultados obtenidos con modelos conexionistas. Este modelo tiene como objetivo explicar la imbricación inconciente-conciente de la metacognición en el aprendizaje de la gramática y brinda valiosas hipótesis sobre los procesos metacognitivos conscientes de su aprendizaje.

En esta misma línea de procesos conscientes e inconscientes del conocimiento metacognitivo, Norman, Price y Duff realizan una discusión sobre el carácter implícito e inconsciente de las sensaciones metacognitivas basadas en la experiencia, como lo son la sensación metacognitiva de "tenerlo en la punta de la lengua" o la sensación de dificultad en el aprendizaje y la resolución de problemas (abordado con mayor detalle por Tourouglou y Efklides en esta misma obra). Específicamente, estos investigadores retoman el concepto de "conciencia marginal" (fringe consciousness) acuñado por William James y discuten sobre las semejanzas y diferencias que posee este concepto con las sensaciones metacognitivas; concluyendo que ambos fenómenos presentan muchos puntos de encuentro que pueden ayudar a resolver la ambigüedad en las investigaciones acerca de sensaciones metacognitivas.

Aunado a lo anterior, Bacon publica en esta misma obra, su investigación acerca de la sensación metacognitiva de "tenerlo en la punta de lengua". En esta indagación, la autora induce a un estado semi amnésico a los sujetos que forman parte del grupo experimental mediante la ingesta de lorazepam, bajo la hipótesis de que los sujetos experimentales presentarían mayor frecuencia de la sensación de "tenerlo en la punta de la lengua" que el grupo control sin ingesta de esta sustancia. Los resultados apoyan esta hipótesis y además, arrojan datos sobre la disociación entre las características fenomenológicas de la cognición y la metacognición.

En este mismo tema, una de las editoras del libro reseñado, retoma otra de las sensaciones metacognitivas basadas en la experiencia; Efklides y Tourouglou abarcan la sensación de "borrado de la mente", la cual ocurre cuando realizamos una tarea y de repente realizamos otra subtarea que nos dificulta recordar cuál era la subtarea previa que se estaba ejecutando. Estas investigadoras se plantean el objetivo principal de investigar el efecto de las demandas de las tareas de memoria proactiva en las experiencias metacognitivas de "borrado de la mente" y "tenerlo en la punta de la lengua". Entre los resultados se encontró un efecto significativo de las demandas de memoria de trabajo elevadas sobre estas experiencias metacognitivas y otros hallazgos son discutidos sobre la memoria prospectiva y su efecto en las experiencias metacognitivas.

Es también destacable el capítulo realizado por Izaute y Bacon acerca de la metamemoria en personas con esquizofrenia, el cual abarca en su primera 
parte una discusión sobre las experiencias metacognitivas, el control y el monitoreo de la memoria en la esquizofrenia. Asimismo, las autoras hacen una breve mención de las creencias metacognitivas acerca de las alucinaciones y sus propios procesos cognitivos en esta población. Finalmente, Izaute y Bacon retoman dos investigaciones empíricas que les permiten afirmar que las personas diagnosticadas con este trastorno no poseen un déficit de monitoreo de la memoria, sino un pobre control metacognitivo de sus propios procesos; habilidad que incluye la confianza en los propios procesos mentales.

En la segunda parte del libro, sobresale por sus aportes metodológicos el capítulo de Whitebread y colaboradores, quienes confeccionan protocolos de observación para niños de 3 años hasta 5 años de edad. Con esto, se supera en gran medida las limitaciones que poseen las estrategias de papel y lápiz más utilizadas en la literatura sobre metacognición. Asimismo, aporta datos provenientes de observaciones que no dependen del autoreporte explícito de las estrategias y demás variables metacognitivas, es decir, permiten captar el carácter inconsciente de algunos de los procesos metacognitivos más estudiados como el monitoreo y el control. Además, como mencionan los autores, al utilizar protocolos confiables de observación con niños pequeños, se pueden realizar relaciones con otras variables que en el pasado no se podían correlacionar (debido a dificultades metodológicas) como los son las funciones ejecutivas; específicamente control inhibitorio y teoría de la mente e integrar en un mismo modelo el desarrollo de la metacognición y estas tres funciones mentales.

Siguiendo con este tópico, Lyons y Ghetti respaldan los hallazgos de Whitebread y colaboradores, desafiando la afirmación que por mucho tiempo se sostuvo en la investigación en metacognición, que aseguraba que los niños prescolares no son "metacognitivamente" habilidosos en comparación con niños mayores. Estos investigadores realizan una revisión de estudios que contradicen este enunciado y ponen sobre la mesa, preguntas fundamentales a ser respondidas tales como: ¿Cómo se desarrollan el control y el monitoreo metacognitivo en la niñez temprana? ¿Cuál es la relación entre control y monitoreo en la niñez temprana? ¿Cuáles son las bases neurales del monitoreo y el control y cómo se desarrollan estas bases en la niñez temprana?

Por último, Misailidi presenta en esta obra un capítulo integrador de la metacognición y el desarrollo de una teoría de la mente. Se trata un intento por unir dos tradiciones de investigación que históricamente han marchado alejadas una de la otra, pero con los avances actuales es posible conciliar estos proyectos de investigación y trazar modelos correlacionales entre ambos. La investigadora deja claro que aún hay mucho por develar respecto a la dirección de la relación entre la metacognición y la teoría de la mente, no obstante, eso no es obstáculo para el desarrollo de investigaciones integradoras con una perspectiva de desarrollo a través del ciclo vital.

Hasta este punto, se han retomado los capítulos más destacados contenidos en la obra de Anastasia Efklides y Pluosia Misailidi, cabe aclarar que no se han mencionado todos los capítulos pues el espacio dedicado a esta 
reseña tiene sus límites, mas no es un libro que retoma las discusiones más relevantes en el estudio de la metacognición. Como se puede apreciar, es una obra con gran variedad de contenidos que convocan a indagar aun más en la teoría y los métodos de estudio de los diversos fenómenos metacognitivos que no son mencionados normalmente en otros libros anteriores tales como "la conciencia marginal".

A pesar de sus fortalezas, el libro "Trends and Prospects in Metacognition Research" deja a un lado las investigaciones realizadas en el área de psicopatología y metacognición, ya que, solo dedica un capítulo a esta temática. Es importante retomar este tipo de estudios para el desarrollo de mejores estrategias de intervención, así como se han desarrollado mejores estrategias de educación basadas en los descubrimientos acerca de la metacognición, como es el caso del programa realizado por Csíkos y Steklács contenido en este libro.

\section{Referencias}

Efklides, A. \& Misailidi, P. (Eds.). (2010). Trends and Prospects in Metacognition Research. New York: Springer. ISBN: 978-14419-6545-5

Flavell, J.H. (1979). Metacognition and cognitive monitoring: A new era of cognitive developmental inquirí. American Pscychologist, 34, 906-911.

Recibido: 01 de febrero de 2012

Aceptado: 25 de febrero de 2012 